\title{
The tools related to mathematics teachers' pedagogical reasoning: critical review
}

\author{
Kai-Lin Yang, Siska Nopa Br Tambunan
}

Department of Mathematics, National Taiwan Normal University, Taiwan.

\begin{abstract}
Shulman (1987) introduced pedagogical reasoning in his model of pedagogical reasoning and action, refers to the phases of activities involving comprehension, transformation, instruction, evaluation, and reflection. The present study aims at a critical review on the tools for investigating the phases of pedagogical reasoning and action for mathematics teachers. Based on a focused search in the database Scopus, 13 articles were reviewed. Findings showed three categories included mathematical tasks, teaching materials and videos. We further classified each category and connected it with Shulman's phases of pedagogical reasoning. Mathematical tasks are classified as pure mathematical tasks and mathematical pedagogical tasks which can be connected to comprehension and transformation phases. Teaching materials are classified into three sub-categories, including materials in planning session, in implementation session, and after implementation which can be connected to comprehension and transformation, instruction, and evaluation and reflection phases, respectively. Lastly, videos are classified into three subcategories including video of self-teaching, others teaching, and movie which connected to evaluation and reflection phases. Two findings are highlighted including (1) the correspondence between the tools for pedagogical reasoning and Shulman's phases of pedagogical reasoning and (2) the features of each sub-category of the tools related to pedagogical reasoning.
\end{abstract}

Keywords: Mathematics teachers; pedagogical reasoning. 


\section{Introduction}

The term of Pedagogical Reasoning was introduced by Shulman (1987) in his model of pedagogical reasoning and action, refers as a process of transforming knowledge, such as transforming the subject content knowledge into teachable content by considering students' diversity of ability and needs. Pedagogical reasoning becomes one of notable aspects of teachers' teaching and learning process that it influences teachers in making decision either in planning, implementation or after implementation sessions. In some conditions, teachers' pedagogical reasoning might be accessible through teacher professional development, such as practice-based and collaboration (Pella, 2015). According to model of activity by Engeström (1999), professional development consists of some components including tools, subject, and object. Herein, the tools for investigating or improving teachers' pedagogical reasoning are critical in the transformation process since they are the key components of the cyclic process of pedagogical reasoning (i.e. Shulman's model). These various tools have their own characteristics in how and when they would be used in teacher education program, which is also discussed in this present study. Therefore, this review paper aims to examine what and how the tools could be employed to enhance teachers' pedagogical reasoning by answering the following questions: (1) What are the tools that investigated and used in these studies related to pedagogical reasoning? And how they connect to Shulman's model of pedagogical reasoning? And (2) What are the features of the tools used for pedagogical reasoning?

\section{Pedagogical Reasoning}

Pedagogical reasoning is defined as the process of developing pedagogical content knowledge, such as starting with initial understanding and shifting with a new understanding of pedagogical content knowledge which influence teachers in making decision. Several actions are involved in pedagogical reasoning, including comprehension, transformation, instruction, evaluation and reflection (Shulman, 1987).

\subsection{Phases of pedagogical reasoning}

Comprehension - "To teach is first to understand" (Shulman, 1987, p.14). It is crucial for a teacher to understand the teaching content themselves and to comprehend a set of ideas in their discipline and how those ideas interrelated and connected within and with other discipline (Nilsson, 2009). Transformation - Transforming the subject knowledge into a teachable content is the most influential process in pedagogical reasoning and action (Starkey, 2010). As the paramount aspect, transformation involves combination of some activities, they are: (1) preparation (2) representation of the ideas (3) instructional selections (4) adaptation of these representations to the general characteristics and (5) tailoring the adaptations to individual student needs (Shulman, 1987). Instruction - The observable 
performances of teacher during teaching moment are comprised in this action (Shulman, 1987). Most of pedagogical aspects of teacher could be seen in this process in how teacher conforms the transformed content in the actual classroom condition, included managing the classroom, delivering clear content, facilitating the discussion/activities, and interacting effectively with pupils through question and answer, compliment, comment or motivation as well. Evaluation - Evaluation follows instruction and that includes checking for students' understanding and misunderstanding during the instruction and testing students in formal or informal way after instruction (Shulman, 1987). Furthermore, it is not only concerning about students, but also evaluating for teacher's instruction such as the gap between teacher and students, teacher and teaching content, and as well as gap between students and teaching material. Reflection - In this action, teacher begins a retrospect of teaching and learning process that has occurred. "The teacher reflected on the lesson in three ways, included pedagogical decision making, how the students engaged in the lesson and the effectiveness of the lesson" (Starkey, 2010, p. 239). Finally, the process of pedagogical reasoning cycles back to gain a new comprehension, which is a new understanding as a result of the learning through the pedagogical actions.

\subsection{The tools used for pedagogical reasoning}

Based on model of activity theory (figure 1) by Engeström (1999, p.30), the tools play a role to mediate the subjects (i.e. teachers) and objects (i.e. teachers' interpretation or knowledge) that produce the outcomes. Herein, the tools for pedagogical reasoning refer to the materials that are observed by participants and require their pedagogical reasoning. Teachers' pedagogical reasoning about the materials may base on their pedagogical content knowledge and then produce teaching and learning. Several examples of the tools for pedagogical reasoning are lesson plan (Nilsson, 2009) for before implementation session, textbook or activity sheets for implementation session (McDuffie \& Mather, 2009), and students' work (Baldinger, 2020) for after implementation. The tools of pedagogical reasoning are useful for teachers if they are employed effectively in teacher education program.

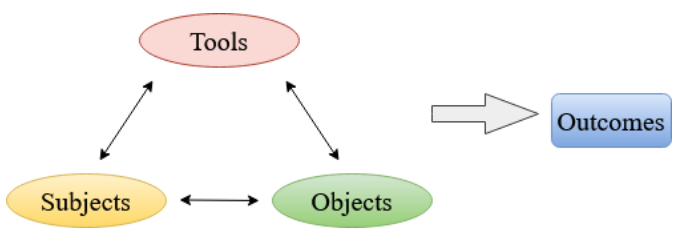

Figure 1. Model of activity, according to Engeström, $Y$.

\section{Method}

The literatures were identified by exploring Scopus database with keywords "pedagogical reasoning" or "curricular reasoning" or "instructional reasoning" or "practical reasoning" or 
"reflective reasoning" or "reasoning * teaching" or "reasoning * learning" or reasoning * student" AND "mathematics" or "mathematical" AND "teacher". The total of 30 articles were located, through the selection process, the 13 articles (Andrews-Larson, Wilson, \& Larbi-Cherif, 2017; Arani, 2017; Aydogan Yenmez, Erbas, Cakiroglu, Cetinkaya, \& Alacaci, 2018; Baldinger, 2020; Chen, Marshall, \& Horn, 2020; Choy, 2016; Dyer \& Sherin, 2016; Horn, 2010; Kim, Metzger, \& Heaton, 2019; Lesseig et al., 2017; McDuffie \& Mather, 2009; Niess \& Gillow-Wiles, 2017; Von Minden, Walls, \& Nardi, 1998) were included in this review study.

\section{Results}

\subsection{The tools for pedagogical reasoning Shulman's phases of pedagogical reasoning}

Based on table 1, we can see the correspondence between the tools of pedagogical reasoning and Shulman's model of pedagogical reasoning. 
Table 1. The connection between tools for and phases of pedagogical reasoning.

\begin{tabular}{|c|c|c|c|c|c|c|}
\hline Tools & hulman's Phases & 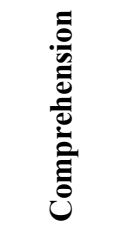 & 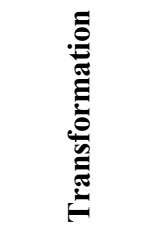 & 莺 & 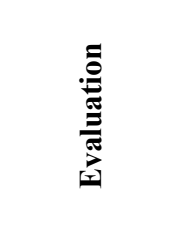 & 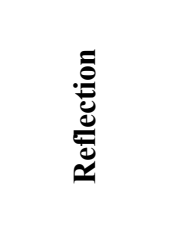 \\
\hline \multirow{2}{*}{$\begin{array}{c}\text { Mathematical } \\
\text { task }\end{array}$} & $\begin{array}{c}\text { Pure } \\
\text { mathematical } \\
\text { tasks }\end{array}$ & $\# 4, \# 13$ & - & - & - & - \\
\hline & $\begin{array}{c}\text { Mathematical } \\
\text { pedagogical task }\end{array}$ & $\# 6$ & $\# 6$, \#13 & - & - & - \\
\hline \multirow{4}{*}{$\begin{array}{l}\text { Teaching } \\
\text { Materials }\end{array}$} & $\begin{array}{l}\text { In Planning } \\
\text { sessions (i.e. } \\
\text { lesson plan) }\end{array}$ & $\# 12$ & $\begin{array}{c}\# 1, \# 3, \# 8, \\
\# 9, \# 11, \\
\# 12\end{array}$ & - & - & - \\
\hline & $\begin{array}{l}\text { In implementation } \\
\text { (i.e. textbook) }\end{array}$ & - & - & $\# 3, \# 11, \# 12$ & - & \\
\hline & $\begin{array}{c}\text { After } \\
\text { implementation } \\
\text { (i.e. students' } \\
\text { work) }\end{array}$ & - & - & - & $\# 3, \# 11, \# 12$ & $\begin{array}{c}\# 3, \# 4, \# 8, \\
\# 11, \# 12\end{array}$ \\
\hline & Self-teaching & - & - & - & $\# 7, \# 12$ & $\# 7, \# 12$ \\
\hline \multirow[t]{2}{*}{ Videos } & Others teaching & - & - & - & $\# 2, \# 10, \# 12$ & $\# 2, \# 10, \# 12$ \\
\hline & Movie & - & - & - & - & $\# 5$ \\
\hline
\end{tabular}

$\mathrm{N}=$ ID number of the articles

For the tools of pedagogical reasoning, findings showed the categories of materials included mathematical tasks, teaching materials and videos. We further classified each material into sub-categories and connected it with Shulman's phases of pedagogical reasoning. Firstly, mathematical tasks are classified as pure mathematical tasks (for teachers) and mathematical pedagogical tasks (for students). Specifically, the pure mathematical tasks can reveal teachers' mathematical reasoning while mathematical pedagogical tasks provide teachers need to reason about the representation of content. Thus, the two sub-categories can be connected to comprehension and transformation phases. Secondly, teaching materials are classified into three sub-categories, including materials in planning session (i.e., lesson plan), in implementation session (i.e., textbooks), and after implementation (i.e., students' work). In planning session, we see teachers' reasoning to engage with the content while teachers' 
instructional reasoning is showed in implementation session. Then, teachers' reasoning is expressed when they evaluate the results of the lesson. These three sub-categories can be connected to comprehension and transformation, instruction, and evaluation and reflection phases, respectively. Lastly, videos are classified into three sub-categories including video of self-teaching, video of others teaching, and film. The videos are included in evaluation and reflection phase, where we could investigate teachers' reflective reasoning about selfteaching and teachers' noticing skills when they watch the video of others teaching.

\subsection{The features of the tools for pedagogical reasoning}

The three tools related to pedagogical reasoning (mathematical tasks, teaching materials, and videos) have some characteristics in the how (the way they used) and when (i.e. before implementation, implementation, and after implementation) they are used in the studies. Firstly, mathematical task is used specifically on session before the implementation. To be confident in delivering the materials to students, teachers would practice with some mathematical tasks before they teach them to their students, especially for novice teachers. For further anticipation, before implementation, teachers are required to transform their mathematical knowledge into teachable content so students can understand the material easily. Secondly, teaching materials can be used before implementation, in implementation, and after implementation. Teaching materials are varied including lesson plan, textbook, teaching tools/apparatus, activity sheets, students' work, etc. the most popular teaching materials that used in the studies is lesson plan. Lesson plan is a concrete evidence to investigate what teachers know and how teachers teach, especially to observe teachers' decision-making and noticing skills. Lastly, the videos are used after implementation process. Usually, video is employed as an object in teachers collaboration time (Arani, 2017; Chen et al., 2020; Dyer \& Sherin, 2016; Lesseig et al., 2017), which offer opportunities for teachers to discuss, reflect and evaluate the teaching and learning process on the videos.

\section{Conclusion}

The results showed three categories of the tools included mathematical tasks (pure mathematical tasks and mathematical pedagogical tasks), teaching materials (planning session, implementation session, and after implementation) and videos (self-teaching, others teaching, and movie). We also further classified each category and connected it with Shulman's phases (i.e. comprehension, transformation, instruction, evaluation and reflection) of pedagogical reasoning. According to the review, two findings are highlighted, including (1) the correspondence between the tools for pedagogical reasoning and Shulman's phases of pedagogical reasoning and (2) the features of each sub-category of the tools of pedagogical reasoning. The former findings could be used by teacher educators as reference to design their materials for investigating and improving teachers' pedagogical reasoning and action. 
Regards the features of sub-categories, it is suggested to further investigate and compare the process of pedagogical reasoning as teachers interact with different category of materials in order to find a more efficient approach to teacher education.

\section{Acknowledgments}

This research was funded by the Ministry of Science and Technology (MOST), Taiwan, R.O.C., under the grant number MOST 107-2511-H-003 -004 -MY3.

\section{References}

Andrews-Larson, C., Wilson, J., \& Larbi-Cherif, A. (2017). Instructional improvement and teachers' collaborative conversations: The role of focus and facilitation. Teacher College Record, 119, 1-37.

Arani, M. R. S. (2017). Raising the quality of teaching through Kyouzai Kenkyuu-the study of teaching materials. International Journal for Lesson and Learning Studies.

Aydogan Yenmez, A., Erbas, A. K., Cakiroglu, E., Cetinkaya, B., \& Alacaci, C. (2018). Mathematics teachers' knowledge and skills about questioning in the context of modeling activities. Teacher Development, 22(4), 497-518.

Baldinger, E. E. (2020). Reasoning about student written work through self-comparison: how pre-service secondary teachers use their own solutions to analyze student work. Mathematical Thinking and Learning, 22(1), 56-78.

Chen, G. A., Marshall, S. A., \& Horn, I. S. (2020). 'How do I choose?': mathematics teachers' sensemaking about pedagogical responsibility. Pedagogy, Culture \& Society, 118.

Choy, B. H. (2016). Snapshots of mathematics teacher noticing during task design. Mathematics Education Research Journal, 28(3), 421-440.

Dyer, E. B., \& Sherin, M. G. (2016). Instructional reasoning about interpretations of student thinking that supports responsive teaching in secondary mathematics. ZDM, 48(1-2), 6982.

Horn, I. S. (2010). Teaching replays, teaching rehearsals, and re-visions of practice: Learning from colleagues in a mathematics teacher community. Teachers College Record, 112(1), 225-259.

Kim, H.-j., Metzger, M., \& Heaton, R. M. (2019). Teacher Planning Sessions as Professional Opportunities to Learn: an Elementary Mathematics Teacher's Re-conceptualization of Instructional Triangles. International Journal of Science and Mathematics Education, 121.

Lesseig, K., Elliott, R., Kazemi, E., Kelley-Petersen, M., Campbell, M., Mumme, J., \& Carroll, C. (2017). Leader noticing of facilitation in videocases of mathematics professional development. Journal of Mathematics Teacher Education, 20(6), 591-619. 
McDuffie, A. R., \& Mather, M. (2009). Middle school mathematics teachers' use of curricular reasoning in a collaborative professional development project. Mathematics teachers at work: Connecting curriculum materials and classroom instruction, 302-320.

Niess, M. L., \& Gillow-Wiles, H. (2017). Expanding teachers' technological pedagogical reasoning with a systems pedagogical approach. Australasian Journal of Educational Technology, 33(3).

Nilsson, P. (2009). From lesson plan to new comprehension: Exploring student teachers' pedagogical reasoning in learning about teaching. European Journal of Teacher Education, 32(3), 239-258.

Pella, S. (2015). Pedagogical Reasoning and Action: Affordances of Practice-Based. Teacher Education Quarterly, 42(3), 81-101.

Shulman, L. S. (1987). Knowledge and Teaching: Foundations of the New Reform. Harvard Educational Review, 57(1).

Starkey, L. (2010). Teachers' pedagogical reasoning and action in the digital age. Teachers and Teaching: theory and practice, 16(2), 233-244.

Von Minden, A. M., Walls, R. T., \& Nardi, A. H. (1998). Charting the links between mathematics content and pedagogy concepts: Cartographies of cognition. The Journal of experimental education, 66(4), 339-358. 